\title{
Perancangan Mesin 3D Printing Model Cartesian
}

\author{
Deny Poniman Kosasih ${ }^{1, a)}$, Hari Din Nugraha ${ }^{2, b)}$, Wahyu Arief Saefullah ${ }^{3, c}$ \\ 1,2,3Program Studi Teknik Mesin Universitas Subang, \\ Jalan R.A. Kartini KM. 3 Subang, Jawa Barat 41285, Indonesia
}

a)denyponiman@gmail.com; (corresponding author), b) haridinnugraha@unsub.ac.id, ${ }^{\text {c) }}$ arif.succes4@gmail.com,

\begin{abstract}
Abstrak
Mesin 3D printing dewasa ini sulit dirancang dan tidak mudah dioperasikan. Penelitian ini bertujuan merancang mesin 3D Printing model cartesian yang mudah dirancang dan digunakan. Penelitian menggunakan jenis penelitian Design-Based-Research (DBR). Dimana proses DBR digunakan untuk merancang dan menguji mesin 3D printing model cartesian. Proses pengujian mesin 3D printing menggunakan bahan Polilactid Acid (PLA merah) dengan filamen diamater $1,75 \mathrm{~mm}$ dan volume $0,4 \mathrm{~mm}$. Hasil penelitian menunjukan bahwa proses perancangan desain mesin 3D printing didapatkan hasil area kerja panjang $30 \mathrm{~cm}$ lebar $30 \mathrm{~cm}$ dan tinggi $30 \mathrm{~cm}$ dengan yang terbagi menjadi rangka utama, rangka bawah, dan rangka atas. Hasil kesesuainan hasil cetak memliliki bentuk geometri sama, namun terdapat stringing pada hasil simulasi produk, hal ini disebabkan karena pengaturan retraksi dan suhu temperatur yang tinggi. Software repeater host dapat direkomenasikan untuk digunakan sebagai simulasi model mesin 3D cartesian karena mudah digunakan dan user friendly. Penelitian ini memberikan dampak pembuatan mesin 3D printing yang mudah dirancang oleh khalayak.
\end{abstract}

Kata kunci: Mesin 3D Printing, Cartesian, additive manufacturing

\begin{abstract}
Today's 3D printing machines are difficult to design and not easy to operate. This study aims to design a Cartesian model $3 D$ Printing machine that is designed and used easily. This research uses the research type DesignBased-Research (DBR). The DBR process is used to design and test a Cartesian model $3 D$ printing machine. The testing process for a 3D printing machine uses Polylactid Acid (red PLA) with a filament diameter of $1.75 \mathrm{~mm}$ and a volume of $0.4 \mathrm{~mm}$. The results show that the process of designing a $3 D$ printing machine design results in a work area that is $30 \mathrm{~cm}$ long, $30 \mathrm{~cm}$ wide and $30 \mathrm{~cm}$ high, which is divided into main frame, underframe, and upper frame. The result of mold conformity has the same geometric shape, but there is stringing in the simulation results, this is due to the high retraction and temperature settings. The host repeater software can be recommended for use as a simulation of a Cartesian $3 D$ machine model because it is easy to use and user friendly. This research has an impact on making a 3D printing machine that is easy for to design.
\end{abstract}

Keywords: 3 D Printing Machine, Cartesian, additive manufacturing

\section{PENDAHULUAN}

Mesin printing $2 D$ saat ini mulai tergantikan dengan adanya mesin 3D Printing. Hal berimplikasi karena semakin beragamnya kebutuhan manusia yang beragam yang melahirkan konsekuensi produk yang dibutuhkan menjadi sangat beragam dan kompleks [1]. Produk yang akan dikembangkan tentunya dimulai dari pembuatan prototype terlebih dahulu. Prototype yang dikembangkan tentunya jika di hasilkan dari objek 2 dimensi belum cukup menggambarkan hasil benda prototype [2].

3D printing merupakan salah satu solusi pembuatan prototype yang sangat mempermudah dalam kegiatan aktivitas manusia. Prototype yang dibuat menghasilkan bentuk yang mendetail, mudah dan cepat [3], [4]. 3D printing dapat mencetak prototype benda secara 3 dimensi ataupun purwarupa. Pada umumnya pembuatan prototype membutuhkan waktu yang cukup lama, mulai dari membuat desain sampai finishing. Dengan adanya 3D printing proses produksi prototype menjadi lebih efisien dalam memangkas waktu [5].

Teknologi 3D printing (Printer 3D) merupakan teknologi manufaktur dalam Revolusi 4.0. 3D printing termasuk ke dalam konsep Additive Manufacturing. Berbeda halnya CNC (Computer Numerically Control) yang melakukan substractive manufacturing. Additive manufacturing merupakan proses menjadikan dalam file digital menjadi suatu objek padat 3 dimensi berdasarkan susunan lapisan (layer) bahan. Tidak seperti proses konstruksi konvensional, bangunan pencetakan 3D diekstrusi oleh lapisan-lapisan nozzle tanpa memerlukan bekisting [6].

Selain itu, Proses 3D printing sendiri merupakan teknologi Fused Deposisi Modelling (FDM) yang merupakan salah satu teknologi manufaktur digital, bahan 
yang meleleh harus diekstrusi dari nozzle pada platform ruang kerja dengan arah tetap [3], [4]. Metode bekerja dengan cara menggunakan nozzle yang dipanaskan sehingga dapat melelehkan material. Nozzle tersebut bergerak secara horizontal, vertikal yang diatur oleh komputer kemudian material yang keluar dari nozzle akan mengeras dan membentuk benda yang diinginkan [7].

Beberapa hasil penelitian sudah dilakukan sebelumnya, diantara pembuatan pencetakan 3D dan fabrikasi filamen yang menyatu digunakan untuk pembuatan prototipe [8]. Selanjutnya rancangan cartesian dengan model pemompoaan yang di kembangkan agar hasil produk mendekati dimensi yang lebih baik [4], [9], [10].

Penelitian ini memfokuskan merancang mesin 3D printing dengan model cartesian. Model cartesian dikembangkan dengan gerakan sumbu cartesian sumbu X, Y, dan Z. material yang digunakan Polilactid Acid (PLA) yang murah dan mudah diakses serta di integrasikan dengan material lain selama pencetakan [11]. $F D M$ dipilih untuk membentuk bentuk aditif yang dapat menghasilkan komponen 3D dari data CAD.

\section{LANDASAN TEORI}

\section{Mesin 3D printing Model Cartesian}

Mesin 3D printing merupakan mesin yang membuat benda padat tiga dimensi dari sebuah desain secara digital untuk menjadi bentuk 3D yang memiliki volume [12]. Salah satu keuntungan penggunaan 3D printer untuk membuat prototyping adalah dapat membuat prototipe dalam waktu yang singkat dan biaya yang murah dibandingkan pembuatan prototipe secara konvensional. Gambar di bawah ini merupakan gambar skematis mesin 3D printing.

Model printing cartesian merupakan mesin 3D printing yang paling umum di pasaran sehingga sering disebut classic printer. Dinamakan model Cartesian karena $3 D$ Printer model ini bekerja dalam tiga dimensi sesuai dengan sistem koordinat dimensi (sumbu $\mathrm{X}, \mathrm{Y}$ di rail ke kiri-kanan, dan sumbu $\mathrm{Z}$ ke atas-bawah) [13]. 3D Printer ini biasanya mempunyai meja kerja berbentuk segi empat.

Beberapa hasil kajian membandingkan hasil komponen pada printer delta memperoleh kualitas permukaan yang lebih baik, sedangkan printer cartesian memberikan akurasi dimensi yang lebih baik. Tiga sampel diproduksi di setiap printer dan dibandingkan berdasarkan kualitas permukaan, waktu pembuatan, massa dan ukuran dimensi. Objek yang dicetak dipindai 3D untuk membandingkan geometri digital dengan menyelaraskan titik cloud yang dihasilkan ke model 3D virtualnya [9].

Model cartesian dengan sumbu X, Y, Z dikembangkan dengan model menggunakan proses FDM [14]. Teknologi FDM sangat ideal untuk pembuatan model fungsional, prototipe atau komponen dalam bahan termoplastik, PLA sehinggal antar elemen muka menyatu [13], [15]. Gambar 1 merupakan gambar model cartesian dimana pergerakan nozzle di atur pergerakannya menurut sumbu cartesian ke arah X memanjang, Y melintang dan $\mathrm{Z}$ vertikal.

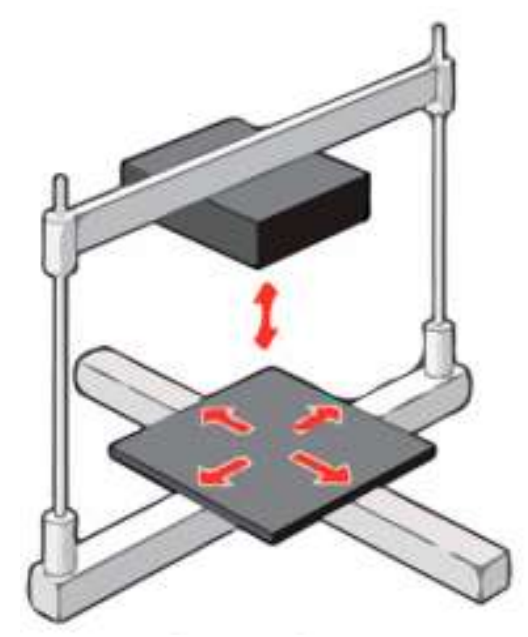

Gambar 1. Skematik Mesin 3D Printing Model Cartesian [9]

Pergerakan mesin 3D printing terjadi karena pencetakan terjadi pada sumbu ortogonal $\mathrm{X}, \mathrm{Y}$, dan $\mathrm{Z}$. Core XY adalah salah satu konfigurasi yang muncul untuk printer cartesian yang menampilkan gerakan nozel ekstruder pada sumbu $\mathrm{X}$ dan $\mathrm{Y}$ dan alas konstruksi bergerak pada sumbu Z. Secara lebih jelas dapat dilihat pada Gambar 2

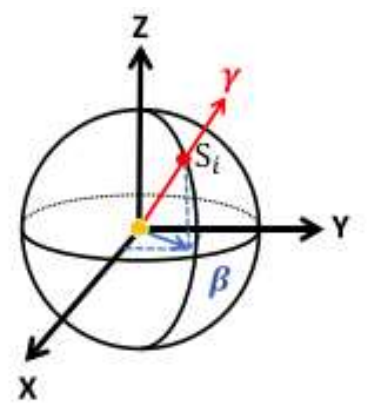

Gambar 2. Pergerakan Sumbu Cartesian pada Mesin 3D [16]

Jenis 3D printer yang digunakan yaitu model Fused Deposition Modelling (FDM), dimana FDM menggunakan bahan nozzle yang dipanaskan dan melelehkan bahan seperti plastik pada hasil outputnya. Nozzle tersebut akan berpindah secara horizontal dan vertikal yang diatur oleh komputer. Ketika material keluar dari nozzle, material tersebut akan mengeras. FDM adalah yang paling populer di antara banyak metode pencetakan 3D, karena mudah dioperasikan dan biaya peralatan terjangkau bagi kebanyakan orang [16], [17]. Gambar 3 merupakan gambar skematik FDM dimana objek dihasilkan dari filamen yanng meleleh dan melunak pada heated liqufier sehingga terjadi proses pencairan. Proses pencairan tersebut diekstrusi dari kepala nosel membentuk lapisan yang membentuk objek sesusai dengan bentuk [18]. 


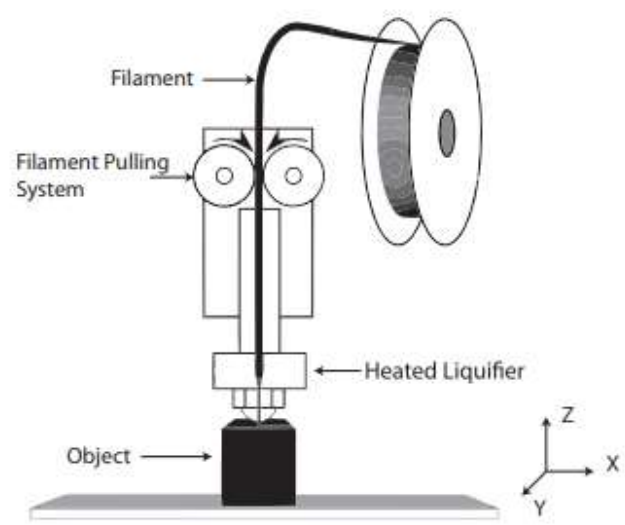

Gambar 2. Skematik Fused Deposition Modelling [18]

\section{Polylactid Acid (PLA)}

Asam polylactic (PLA) adalah salah satu polimer yang paling banyak digunakan dalam teknologi pencetakan 3D [19]. PLA adalah poliester alifatik biodegradable yang berasal dari asam laktat, diekstraksi dari gula, singkong, pati jagung. PLA merupakan termoplastik yang disusun oleh rantai poliester alifatik linier yang disintesis dari sumber daya terbarukan, larut dalam tetrahidrofuran, pelarut terklorinasi, benzena panas dan dioksan, dapat terurai secara alami, berlangsung dari enam bulan hingga dua tahun di lingkungan dan juga tidak berbahaya jika terhidrolisis, memfasilitasi pembuangan akhirnya [11].

PLA memiliki sifat yang sangat baik seperti kekuatan dan kekerasan tinggi, terbarukan, dan toksisitas rendah. Selain itu, kemampuan proses, menggunakan teknologi pemrosesan tradisional, seperti ekstrusi, cetakan injeksi, cetakan kompresi, dan pukulan pencetakan, memperluas aplikasinya [20]. Oleh sebab itu, pada mesin 3D printing sangat cocok digunakan sebagai bahan dasar objek hasil printer dimana pemrosesan lebih mudah dilakukan [21].

\section{METODE PENELITIAN/EKSPERIMEN}

Penlitian menggunakan jenis penelitian Design-BasedResearch (DBR). DBR dipilih karena pendekatan peneitian ini berfokus untuk mengembangkan mesin 3D Printing yang dimulai dengan tahapan analisis masalah, mengkaji literatur, mendesain prototype, merakit, dan analisis sistem mesin 3D printing. Gambar 3 di bawah ini terdapat diagram alir penelitian yang dapat menjelaskan urutan proses penelitian.

Diagram alir Gambar 3 mendeskripsikan tahapan prosedur penelitian. Tahap pertama dimulai dari penelusuran studi literature dengan mengkaji berbagai jurnal sebagai fondasi awal penelitian. Pembuatan desain dilakukan secara terencana mulai dari menentukan persiapan bahan dan alat, pengecekan dan pembuatan jobsheet, pembuatan komponen mekanis, dan terakhir pembuatan komponen elektris. Semua komponen kemudian di finishing terlebih dahulu sebelum dilakukan digabungkan atau assembly secara keseluruhan.

Tahap akhir yaitu melakukan pengujian kinerja untuk melihat performansi dari alat tersebut. Dari hasil pengujian didapatkan beberapa kekurangan yang kemudian langsung diperbaiki. Pada bagian akhir, jika alat sudah dapat digunakan dengan baik maka pengujian dianggap telah selesai. Secara lebih jelas dapat dilihat pada Gambar 3. Diagram alir penelitian sebagai berikut.

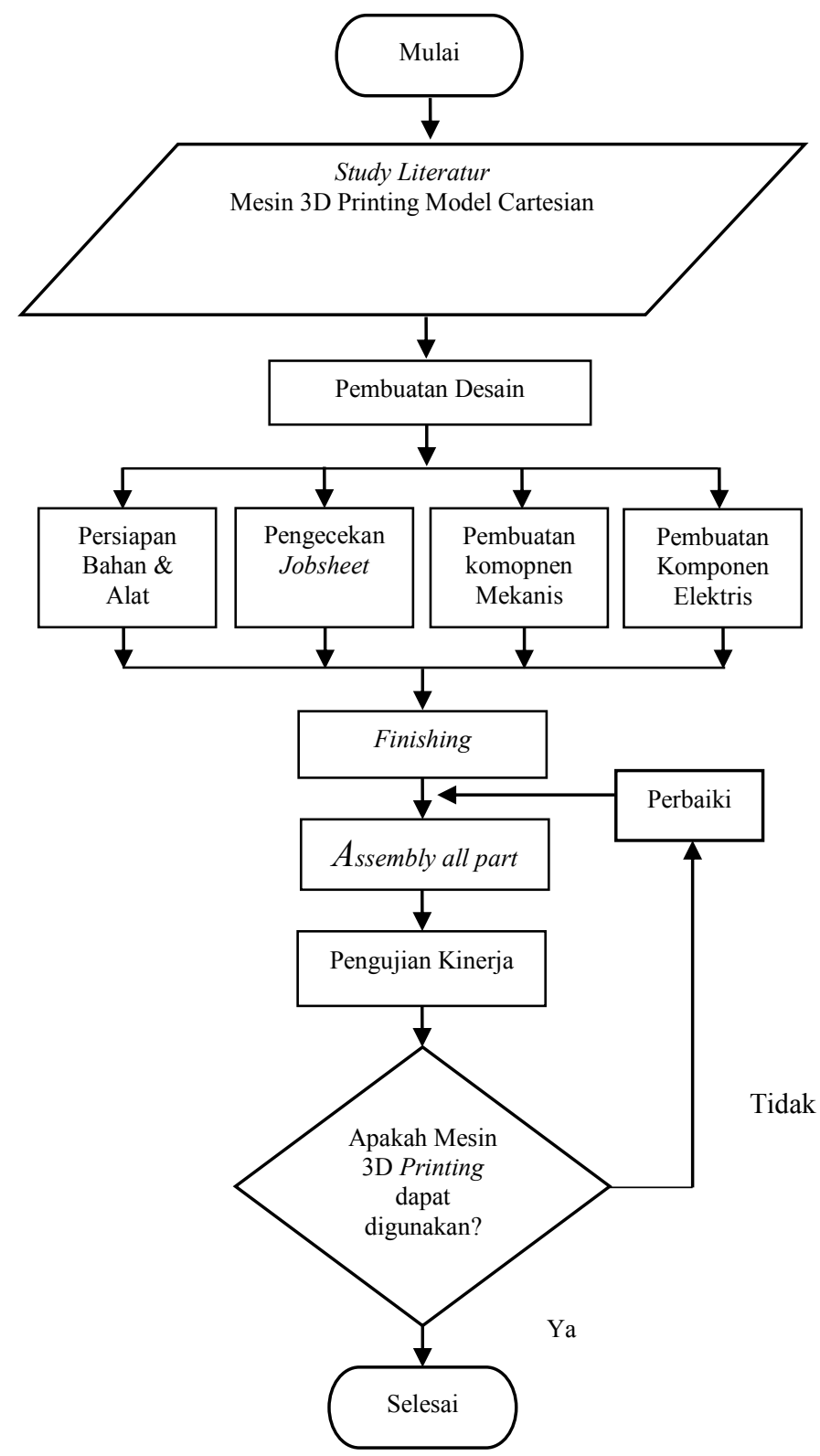

Gambar 3. Diagram Alir Penelitian

Perancangan desain 3D printing model cartesian menghasilkan komponen utama rangka mesin 3D printing terdiri dari komponen mekanis dan komponen elektrik. Sebelum menguraikan komponen mekanis desain area kerja pada mesin ditentukkan terlebih dahulu. Area kerja yang digunakan memiliki panjang $30 \mathrm{~cm} \mathrm{x}$ lebar $30 \mathrm{~cm}$ x tnggi $30 \mathrm{~cm}$. Sehingga dari rencana area kerja tersebut bisa ditentukan komponen mekanis, komponen rangka utama dan pelengkap lainya. Rangka utama dibagi menjadi 3 bagian yakni base, gantry dan guide rel untuk heatbed. Secara lebih khusus, penelitian 
ini menghasilkan spesifikasi 3D printing disajikan pada Tabel 1.

Tabel 1. Spesifikasi Mesin 3D Printing Model Cartesian

\begin{tabular}{lll}
\hline No & Jenis & Spesifikasi \\
\hline 1 & Printing Type & Cartesian \\
2 & Rangka & Alumunium Profil V \\
& & Slot 2020 \\
& Alumunium Profil V & Slot 2040 \\
& & V Wheel Derlin type \\
& & B dan C \\
3 & Rail Utama & $30 \mathrm{~cm} \mathrm{x} \mathrm{30} \mathrm{cm}$ \\
& & $150 \mathrm{Watt} \& 12 \mathrm{~V}$ \\
4 & Heat Bed & $60 \mathrm{~cm} \times 46 \mathrm{~cm} \times 52$ \\
5 & Power supply & cm \\
6 & Rangka & $8 \mathrm{~mm}-2 \mathrm{~mm}$ Pitch 4 \\
& & start \\
7 & Lead Trapezoidal Screw & GT2 $6 \mathrm{~mm}-2 \mathrm{~mm}$ \\
& & Pitch \\
8 & Belt & 16 Teeth GT2 \\
& & Nema 17 \\
9 & Pulley & X min $-\mathrm{Y} \mathrm{min}-\mathrm{Z}$ \\
10 & Stepper Motor & max \\
11 & Limit Switch & Proximity sensor \\
& & PLA \\
12 & Automatic Bed Leveling & \\
13 & Printing Material &
\end{tabular}

Setelah di dapat spesfikasi memilih komponen standar yang digunakan, langkah selanjutnya adalah merancang bentuk rangka dan sistem geraknya melalui aplikasi Computer Aided Design (CAD). Proses penggambaran desain meliputi penggambaran rangka utama, rangka bawah dan gambar detail komponen. Secara lebih detail hasil design perancangan ditampilkan pada Gambar 4.
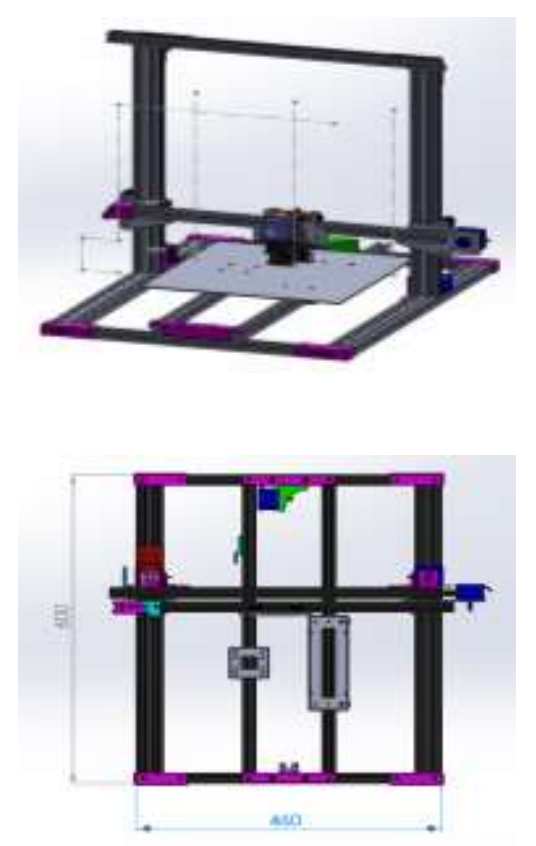

Gambar 4. Desain Rangka Mesin 3D Printing Menggunakan Software Autocad
Secara terperinci rangka mesin 3D printing terdiri dari rangka bawah, rangka atas dan rangka utama. Rincian komponen dijabarkan sebagai berikut.

1. Rangka bawah

- $\quad$ Batang alumunium profile $20 \times 20 \times 360 \mathrm{~mm}=4$ buah

- $\quad$ Corner fitting $=4$ buah

- $\quad$ Baut + M5 x $10 \mathrm{~mm}=8$ buah

- $\quad$ Ring plat $=8$ buah

- $\quad$ Ring per $=8$ buah

- $\quad$ Hammer nut $=8$ buah

- $\quad$ Printed Part Axis $Y=1$ buah

- $\quad$ Mur atau Nut M3 = 1 buah

- $\quad$ Baut + M5 x $10 \mathrm{~mm}=4$ buah

- $\quad$ Hammer nut $=4$ buah

- $\quad$ Printed part Bracket Motor Stepper Y $=1$ buah

- $\quad$ Baut + M3 x $10 \mathrm{~mm}=4$ buah

- $\quad$ Ring plat M3 = 12 buah

- $\quad$ Motor Stepper nema $17=1$ buah

- $\quad$ Pulley GT2 = 1 buah

2. Rangka atas

- $\quad$ Batang alumunium profil $20 \times 20 \times 360=1$ buah

- Batang alumunium profil $20 \times 20$ × $320=2$ buah

- $\quad$ Corner fitting $=2$ buah

- $\quad$ Baut + M5 X $10 \mathrm{~mm}=4$ buah

- $\quad$ Ring plat M5 = 4 buah

- $\quad$ Hammer nut $=4$ buah

- $\quad$ Printed Part Bracket Axis X1 = 1 buah

- $\quad$ Motor Stepper nema $17=1$ buah

- $\quad$ Baut + M3 x 20 = 3 buah

- $\quad$ Mur atau nut M5 = 1 buah

- $\quad$ Linear bearing LM 8 UU $=2$ buah

- $\quad$ Pulley timing belt GT2 = 1 buah

- $\quad$ Printed Part Bracket Axis X2 = 1 buah

- Printed part belt idler axis $X=1$ buah

- $\quad$ Baut + M3 x $25=2$ buah

- $\quad$ Mur atau nut M5 = 1 buah

- $\quad$ Mur atau nut M3 = 2 buah

- $\quad$ Mur atau nut M4 = 1 buah

- $\quad$ Ring plat M4 = 6 buah

- $\quad$ Baut + M4 x 20=1 buah

- $\quad$ Linear bearing LM 8 UU $=2$ buah

- $\quad$ Bearing $624 Z Z=1$ buah

- $\quad$ Printed Part extruder carriage $=1$ buah

- $\quad$ Kabel ties $=6$ buah

- $\quad$ Linear bearing LM 8 UU $=2$ buah

- $\quad$ Linear bearing LM 8 UU long $=1$ buah

- $\quad$ Shaft diameter $8 \mathrm{~mm} \times 360 \mathrm{~mm}=2$ buah

- $\quad$ Timing belt GT2 = potong secukupnya

3. Rangka utama

- Baut + M3 x $20 \mathrm{~mm}=2$ buah

- Mur atau nut M3 = 1 buah

- $\quad$ Ring plat M3 = 7 buah

- Linear bearing LM 8 UU $=4$ buah

- Shaft guide rel dia $.8 \times 390 \mathrm{~mm}=2$ buah

- Timing belt GT 2 = potong secukupnya

- Bearing 624ZZ = 1 buah

- Printed part idler belt (pengatur kekencangan belt) $=1$ buah 
Prosedur uji kinerja mesin 3D printing cartesian

Penelitian ini bertujuan merancang mesin 3D printing model cartesian serta mengetahui kualitas hasil cetak produk. Teknik pengumpulan yang digunakan yaitu dokumentasi dan observasi. Jenis sumber data primer dikumpulkan pada saat pengujian mesin 3D printing dilakukan. Pengujian kinerja alat dilakukan di bengkel Teknik Mesin Universitas Subang. Seacara lebih jelas tahapan pengujian dijelaskan sebagai berikut.

1. Merancang desain 3D printing model cartesian menggunakan software Autodesk

2. Menyiapkan komponen dan jenis bahan sesuai desain

3. Merakit komponen hingga mesin 3D printing

4. Pengujian kinerja menggunakan aplikasi repitier house

5. Pengujian mesin 3D printing diuji menggunakan bahan PLA merah dengan filamen diamater 1,75 $\mathrm{mm}$ dan volume $0,4 \mathrm{~mm}$

6. Pengujian dilakukan dengan membandingkan parameter kesesuain hasil cetak mesin 3D printing

7. Menganalisis hasil cetak

\section{HASIL DAN PEMBAHASAN}

Hasil Perancangan Mesin 3D Printing Model Cartesian

Proses perancangan gambar terdiri dari tiga langkah. Langkah pertama yaitu menggambar area kerja atau meja kerja dengan ukuran $35 \mathrm{~cm}$ x $35 \mathrm{~cm}$. Kemudian buat rangka base dengan panjang minimal dua kali dari panjang meja kerja. Hal tersebut berdasarkan analisis agar mencukupi travel gerak meja kerja pada saat digunakan. Proses pembuatan gambar dilakukan secara berurutan yakni mulai dari rangka base untuk rel axis Y, lalu menggambar rangka gantry yang akan digunakan sebagai rel axis $Z$ dan terakhir menggambar rel untuk axis $\mathrm{Y}$ serta batang rel untuk axis $\mathrm{Z}$. selain itu, rangka bawah atau base berukuran $60 \mathrm{~cm}$ x $46 \mathrm{~cm}$ menggunakan alumunium profil 2040 dan 2020. Baut M5 dan corner join digunakan sebagai penghubung tiap rangka. Masing masing sudut menggunakan corner join 1 dan 2 buah baut M5 x 15 dan Hammer Nut M5 juga 2 buah (Gambar 6)

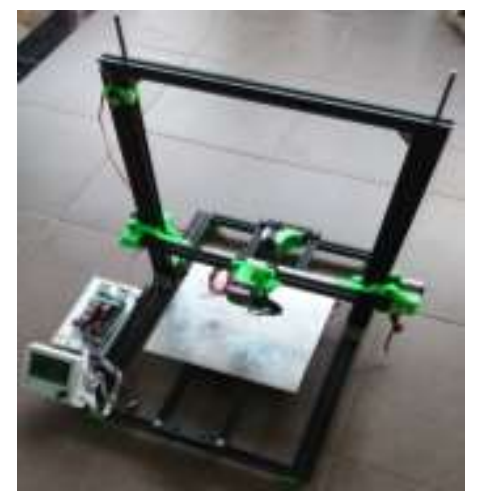

Gambar 6. Hasil Pembuatan Alat Mesin 3D Printing Model Cartesian
Pada Gambar 6 di atas merupakan hasil akhir perakitan akhir mesin 3D printing model cartesian. Setelah melalui proses penggambaran kemudian komponen dibuat dan dipasang sesuai dengan design pada gambar. Proses assembly komponen dilakukan secara bertahap mulai dari pemasangan komponen rangka, pemasangan komponen mekanais dan komponen pendukung lainnya. Sehingga hasil assembly ini dapat dilakukan pengujian pada mesin 3D printing.

Penggunaan Aplikasi Repeater host pada mesin 3D Printing

Pegujian mesin 3D printing menggunakan aplikasi repitier host. Software ini dapat digunakan sebagai simulasi model cartesian yang dibuat. Keuntungan lain adalah pengguna memiliki keleluasaan untuk mengontrol parameter dari keseluruhan proses fabrikasi [22]. Lebih spesifik, repitier host ini memberikan rekomendasi apakah cukup ruang untuk dilakukan proses printing atau tidak. Penggunaan repitier host cukup user friendly karena mudah dimengerti dan banyak sumber tutorial yang dapat diakses. Tahapan penggunaan software repitier host ini dimulai dari proses penginstallan software, konfigurasi sotware, manipulasi objek 3D. Di bawah ini merupakan gambar tahapan penggunaan software Repitier host.

Sebelum proses penginstallan software ada beberapa prasyarat yang dipenuhi agar repietier dapat dipasang pada komputer/laptop. Pertama pada operating system: Minimal Windows 7 dan Netframe work 4.0. Jika menggunakan microcontroller Atmega 2560 - CH340 maka harus instal dulu driver $\mathrm{CH} 340$. Kedua, untuk Graphic Card minimal Open GL 1,5 agar dapat memproses proses rendering objek 3D. ketiga memory penyimpanan RAM pada PC atau Laptop minimal $2 \mathrm{~Gb}$. Jika beberapa prayarat sudah terpenuhi maka proses penginstallan dapat dilakukan.

Proses konfigurasi dimulai dengan mengkonesikan unit printer dengan kabel USB sehingga tanda pada icon berubah menjadi connect. Selanjutnya konfigurasi printer bisa dilakukan kesesuaian dengan mesin printer yang digunakan. Beberapa konfigurasi yang bisa dilakukan diantaranya; mengatur banyak ekstruder, benyaknya kipas, pengaturan suhu maksimal nozzle pada ekstruder, suhu maksimal pada heated bed, mengatur maximal volume filament di extrude dan, mengatur ukuran diameter nozzle yang digunakan untuk cetak. Konfigurasi printer lainya yaitu mengatur posisi home $X$, $Y$ dan $Z$, mengatur gerakan minimal dan maksimal tiap axis, serta mengatur area kerja pada mesin yang digunakan (panjang, lebar, dan tinggi).

Proses yang terakhir yaitu, memanipulasi objek dimana pada konfigurasi software dapat dilakukan masuk ke menu Object Placement yang akan dicetak. Objek yang akan dicetak dapat dimasukkan, copy-paste, maupun pengaturan objek 3D seperti skala, rotasi, mirror dan lain sebagainya. Bahkan pada konfigurasi dapat melihat objek secara jelas dalam berbagai pandangan, seperti pandangan atas, depan, samping, serta isometri. 
Selain itu, pada menu Manual Control untuk mengatur printer 3D secara manual, bisa atur juga; gerakan tiap Axis X Y, memberikan perintah melalui konsol G-Code, Memeriksa gerakan tiap Axis dan fungsi komponen printer, Memeriksa fungsi heatbed. Memeriksa fungsi nozzle dan extruder.

Tahapan pertama adalah instalasi software Repeater host pada laptop. Beberapa aspek standar yang harus dimiliki laptop diantaranya; windows 7 , network work 4.0, microcontroller atmega 2560-CH340, RAM pada PC minimal $2 \mathrm{~Gb}$. Jika sudah dilakukan instalasi, maka langkah berikut mengatur interface seperti menu bar, general menu, view area, control area, log output windows, status line. Pada Gambar 7 disajikan model pengaturan interface.

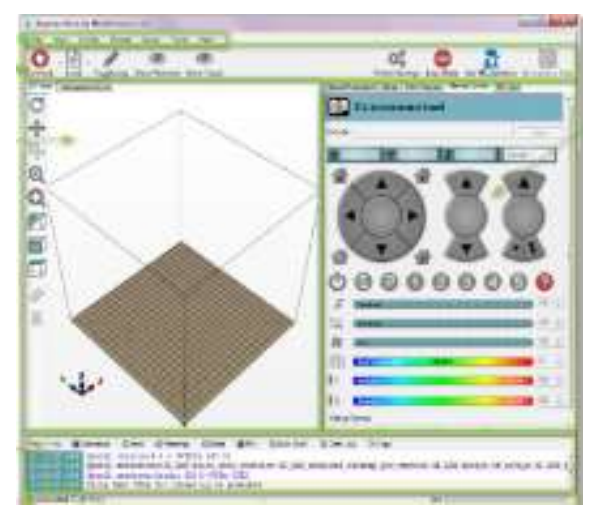

Gambar 7. Pengaturan Interface

Tahap selanjutnya yaitu mengkoneksikan software dengan unit printer menggunakan kabel USB. Mengatur konesksi bertujuan untuk mengatur kesesuaian software dengan printer yang digunakan (Gambar 8).

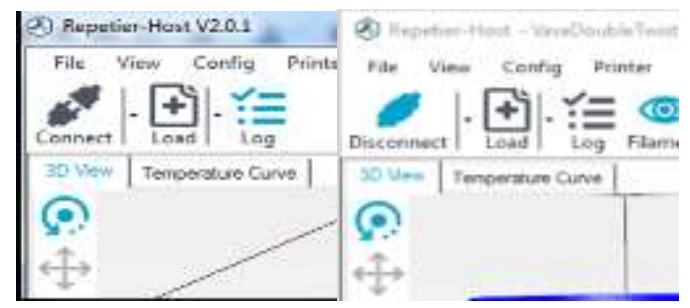

Gambar 8. Pengaturan Konfigurasi

Pengaturan printer pada Gambar 9, dapat dilakukan dengan mengatur paramater banyak ekstruder, benyak kipas yang digunakan, mengatur suhu maksimal nozzle, suhu bed, volume filamen dan diamater noozle. Pada penelitian ini diamter ektruder $0,4 \mathrm{~mm}$, maksimal suhu bed $120^{\circ} \mathrm{C}$, maksimal suhu ekstruder $280^{\circ} \mathrm{C}$ serta volume $12 \mathrm{~mm}^{3} / \mathrm{s}$. selain itu, mengatur posisi $\mathrm{X}, \mathrm{Y}$, dan $\mathrm{Z}$ dengan menggerakan minimal dan maksimal tiap axis. Dan terakhir, mengatur area cetak pada mesin 3D printing.

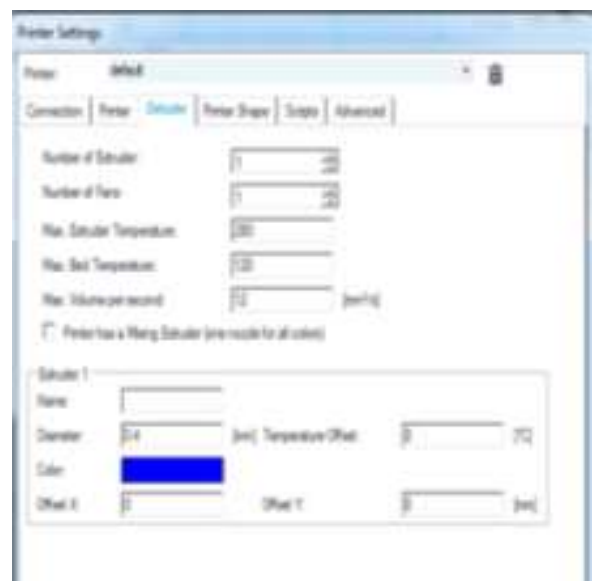

Gambar 9. Pengaturan Printer

Proses terakhir (Gambar 10) yaitu manipulasi objek 3D yang akan cetak, pada menu ini bisa diatur objek yang akan dicetak, copy objek, mengatur (rotasi, skala, pencerminan), dan melihat dari berbagai pandangan (atas, samping, isometri).

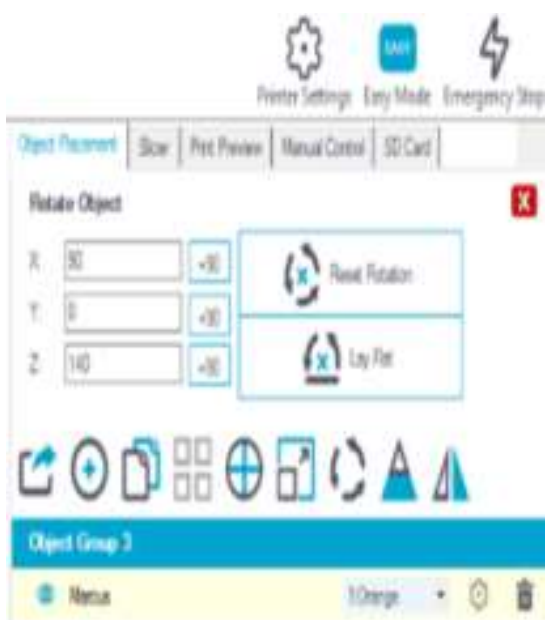

Gambar 10. Pengaturan Manipulasi Objek

Analisis Hasil Stringing pada Mesin 3D Printing

Pada pengujian mesin 3D dilakukan dengan menguji membuat sebuah produk. Gambar 11 merupakan hasil uji coba pengujian mesin 3D printing.

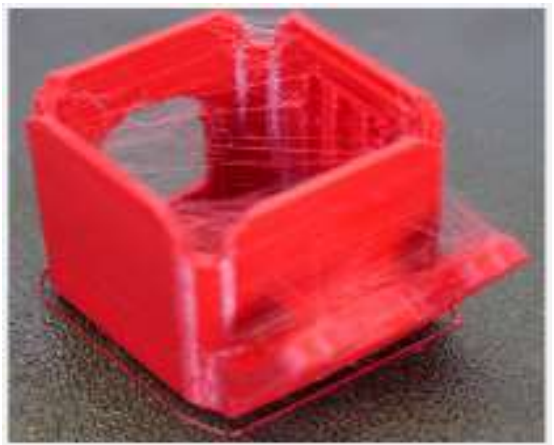

Gambar 11. Stringing pada hasil cetak mesin 3D printing model cartesian 
Hasil pengujian mesin 3D printing yang dilakukan ternyata membuktikan terrdapat masalah pada hasil cetak. Hasil cetak pada mesin 3D printing terdapat stringing. Stringing sendiri yitu keadaan dimana ketika printing dilakukan, timbul adanya sisa plastik yang keluar dari nozzle ketika perpindahan dari satu lokasi ke lokasi lain [23] . Munculnya benang plastik yang tipis yang seharusnya tidak dicetak ultimaker dan print head harusnya hanya melintas dari satu area ke area yang lain.

Hasil analisis membuktikan adanya stringing salah satunya berasal dari printing beberapa objek sekaligus, pengaturan retraksi dan temperatur terlalu tinggi. Temperatur yang tinggi menyebabkan filamen akan menjadi terlalu cair dan akan terlalu mudah keluar dari nozzle dan hal ini dapat menyebabkan terdapat benangbenang pada hasil cetak 3D [24]. Oleh sebab itu jika suhunya terlalu tinggi, plastik di dalam nozzle akan menjadi tidak kental dan akan keluar lebih mudah dari nozzle. Namun, jika suhu terlalu rendah, plastik lebih padat dan akan kesulitan mengekstrusi dari nozzle.

Selain itu, pengaturan retraksi juga dapat mempengaruhi hasil stringing pada hasil cetak 3D printing. Jarak retraksi sangat menentukan banyaknya plastik yang ditarik keluar dari nozzle. Sehingga, semakin banyak plastik yang ditarik dari nozzle, semakin kecil kemungkinan nozzle mengalir saat bergerak. Sebagian besar pengekstrusi penggerak langsung hanya memerlukan jarak retraksi 0,5-2,0mm, sementara beberapa pengekstrusi memerlukan jarak retraksi setinggi $15 \mathrm{~mm}$ karena jarak yang lebih jauh antara gigi penggerak pengekstrusi dan nozzle yang dipanaskan.

\section{KESIMPULAN}

Hasil penelitian membuktikan proses perancangan Hasil penelitian menunjukan bahwa proses perancangan desain mesin 3D printing didapatkan hasil area kerja panjang $30 \mathrm{~cm}$ lebar $30 \mathrm{~cm}$ dan tinggi $30 \mathrm{~cm}$ dengan yang terbagi menjadi rangka utama, rangka bawah, dan rangka atas. Hasil kesesuainan hasil cetak memliliki bentuk geometri sama, namun terdapat stringing pada hasil simulasi produk, hal ini disebabkan karena pengaturan retraksi dan suhu temperatur yang tinggi. Software repitier host dapat direkomenasikan untuk digunakan sebagai simulasi model mesin 3D cartesian karena mudah digunakan dan user friendly. Penelitian ini memberikan dampak pembuatan mesin $3 \mathrm{D}$ printing yang mudah rancang oleh klayak pembaca.

\section{UCAPAN TERIMA KASIH}

Terimakasih kepada Jurusan Teknik Mesin Universitas Subang yang telah membantu dan memfasilitasi penelitian ini sehingga dapat berjalan dengan baik dan lancar.

\section{REFERENSI}

[1] H. Yuk et al., 3D printing of conducting polymers, Nat. Commun., vol. 11, no. 1, 2020, pp. 4-11, doi: 10.1038/s41467-020-15316-7.

[2] J. Skowyra, K. Pietrzak, and M. A. Alhnan, Fabrication of extended-release patient-tailored prednisolone tablets via fused deposition modelling (FDM) 3D printing, Eur. J. Pharm. Sci., vol. 68, no. November, 2015, pp. 11-17, doi: 10.1016/j.ejps.2014.11.009.

[3] B. J. Brooks, K. M. Arif, S. Dirven, and J. Potgieter Robot-assisted 3D printing of biopolymer thin shells, Int. J. Adv. Manuf. Technol., vol. 89, no. 1-4, 2017, pp. 957-968, doi: 10.1007/s00170-016-9134-y.

[4] M. Kaszyńska et al., Evaluation of suitability for 3D printing of high performance concretes, MATEC Web Conf., vol. 163, 2018, pp. 1-8, doi: 10.1051/matecconf/201816301002.

[5] A. A. Nurul Amri and W. Sumbodo, Perancangan 3D Printer Tipe Core XY Berbasis Fused Deposition Modeling (FDM) Menggunakan Software Autodesk Inventor 2015, J. Din. Vokasional Tek. Mesin, vol. 3, no. 2, 2018 pp. 110-115, doi: 10.21831/dinamika.v3i2.21407.

[6] Y. Zhang, Y. Zhang, W. She, L. Yang, G. Liu, and Y. Yang, Rheological and harden properties of the highthixotropy 3D printing concrete, Constr. Build. Mater. vol. 201, 2019, pp. 278-285, doi: 10.1016/j.conbuildmat.2018.12.061.

[7] M. Abdul and M. Amrullah, Rancang Bangun Prototipe Printer 3 Dimensi ( 3D ) Tipe Cartesian Berbasis Fused Deposition Modelling ( Fdm ) Naskah Publikasi Tugas Akhir, 2018.

[8] Y. Tlegenov, G. S. Hong, and W. F. Lu, Nozzle condition monitoring in 3D printing, Robot. Comput. Integr. Manuf., vol. 54, no. December 2017, pp. 45-55, 2018, doi: 10.1016/j.rcim.2018.05.010.

[9] B. M. Schmitt, C. F. Zirbes, C. Bonin, D. Lohmann, D. C. Lencina, and A. Da Costa Sabino Netto, A comparative study of cartesian and delta $3 \mathrm{~d}$ printers on producing PLA parts, Mater. Res., vol. 20, 2017, pp. 883-886, doi: 10.1590/1980-5373-mr-2016-1039.

[10] A. Prakasa, S. P. Sutisna, and A. R. Ahmad, Penentuan Setting Optimal Mesin 3D Printer Berbasis Fused Deposition Modeling Menggunakan Metode Taguchi, AME (Aplikasi Mek. dan Energi) J. Ilm. Tek. Mesin, vol. 4, no. 2, 2018, doi: 10.32832/ame.v4i2.1538.

[11] G. Gaal et al., Simplified fabrication of integrated microfluidic devices using fused deposition modeling 3D printing, Sensors Actuators, B Chem., vol. 242, 2017, pp. 35-40, doi: 10.1016/j.snb.2016.10.110.

[12] S. Mocahmad Diki Muliyawan, Gatoto Eka Pramono, Rancang Bangun Konstruksi Rangka Mesin 3D Printer Tipe Cartesian Berbasis Fused Deposition Modelling (FDM), J. Tek. Mesin, vol. 3, no. 4, 2017, pp. 252-257.

[13] P. J. Nuñez, A. Rivas, E. García-Plaza, E. Beamud, and A. Sanz-Lobera, Dimensional and Surface Texture Characterization in Fused Deposition Modelling (FDM) with ABS plus, Procedia Eng., vol. 132, 2015, pp. 856-863, doi: 10.1016/j.proeng.2015.12.570.

[14] R. Melnikova, A. Ehrmann, and K. Finsterbusch, 3D printing of textile-based structures by Fused Deposition Modelling (FDM) with different polymer materials, IOP Conf. Ser. Mater. Sci. Eng., vol. 62, no. 1, 2014, doi: 10.1088/1757-899X/62/1/012018.

[15] G. Cicala et al., Comparison of Ultem 9085 used in fused deposition modelling (FDM) with polytherimide blends, Materials (Basel)., vol. 11, no. 2, 2018, doi: 10.3390/ma11020285.

[16] R. C. Luo, L. C. Hsu, T. J. Hsiao, and Y. W. Perng, 3D Digital Manufacturing via Synchronous 5-Axes Printing for Strengthening Printing Parts, IEEE Access, vol. 8, 2020, pp. 126083-126091, doi: 10.1109/ACCESS.2020.3007772.

[17] Luki Aditya, PROTOTIPE 3D PRINTER BERBASIS 
MIKROKONTROLER, President University, 2019.

[18] O. S. Carneiro, A. F. Silva, and R. Gomes, Fused deposition modeling with polypropylene, Mater. Des., vol. 83, 2015, pp. 768-776, doi: 10.1016/j.matdes.2015.06.053.

[19] S. R. Rajpurohit and H. K. Dave, Flexural strength of fused filament fabricated (FFF) PLA parts on an opensource 3D printer, Adv. Manuf., vol. 6, no. 4, 2018, pp. 430-441, doi: 10.1007/s40436-018-0237-6.

[20] K. Hamad, M. Kaseem, H. W. Yang, F. Deri, and Y. G. Ko, Properties and medical applications of polylactic acid: A review, Express Polym. Lett., vol. 9, no. 5, 2015, pp. 435-455, doi: 10.3144/expresspolymlett.2015.42.

[21] N. Li, Y. Li, and S. Liu, Rapid prototyping of continuous carbon fiber reinforced polylactic acid composites by 3D printing, J. Mater. Process.
Technol., vol. 238, 2016, pp. 218-225, doi: 10.1016/j.jmatprotec.2016.07.025.

[22] N. A. Bin Sukindar, M. K. A. M. A. Bin, B. T. B. Hang Tuah Bin, C. N. A. J. Binti, and M. I. S. I. Bin, Analysis on the impact process parameters on tensile strength using $3 \mathrm{~d}$ printer repetier-host software, $A R P N$ J. Eng. Appl. Sci., vol. 12, no. 10, 2017, pp. 33413346.

[23] A. Elkaseer, S. Schneider, and G. Scholz, Applied sciences experiment-based process modeling and optimization for high-quality and resource-Efficient, Appl. Sci., 2020.

[24] Z. Rahman, S. F. Barakh Ali, T. Ozkan, N. A. Charoo, I. K. Reddy, and M. A. Khan, Additive manufacturing with 3D printing: Progress from Bench to Bedside, AAPS J., vol. 20, no. 6, 2018, pp. 2-14, doi: 10.1208/s12248-018-0225-6. 